\title{
Improved electron collection in fullerene via caesium iodide or carbonate by means of annealing in inverted organic solar cells
}

\author{
Zouhair El Jouad ${ }^{1,2}$, Guy Louarn ${ }^{3}$, Thappily Praveen ${ }^{4}$, Padmanabhan Predeep ${ }^{4}$, Linda Cattin ${ }^{3}$, \\ Jean-Christian Bernède ${ }^{1, a}$, Mohammed Addou $^{2}$, and Mustapha Morsli ${ }^{5}$ \\ 1 L'UNAM, Université de Nantes, MOLTECH-Anjou, CNRS, UMR 6200, 2 rue de la Houssinière, BP 92208, \\ 44000 Nantes, France \\ 2 Laboratoire Optoélectronique et Physico-chimie des Matériaux, Université Ibn Tofail, Faculté des Sciences, BP 133, \\ 14000 Kenitra, Morocco \\ 3 Université de Nantes, Institut des Matériaux Jean Rouxel (IMN), CNRS, UMR 6502, 2 rue de la Houssinière, \\ BP 32229, 44322 Nantes Cedex 3, France \\ 4 Laboratory for Unconventional Electronics and Photonics, Department of Physics, National Institute of Technology, \\ 673601 Calicut, Kerala, India \\ 5 L'UNAM, Université de Nantes, Faculté des Sciences et des Techniques, 2 rue de la Houssinière, BP 92208, \\ 44000 Nantes, France
}

Received: 27 November 2013 / Received in final form: 14 January 2014 / Accepted: 16 January 2014 Published online: 6 May 2014

(c) El Jouad et al., published by EDP Sciences, 2014

\begin{abstract}
Inverted organic photovoltaic cells (IOPVCs), based on the planar heterojunction $\mathrm{C}_{60} / \mathrm{CuPc}_{\text {, }}$ were grown using $\mathrm{MoO}_{3}$ as anode buffer layer and CsI or $\mathrm{Cs}_{2} \mathrm{CO}_{3}$ as cathode buffer layer (CBL), the cathode being an ITO coated glass. Work functions, $\Phi_{f}$, of treated cathode were estimated using the cyclic voltammetry method. It is shown that $\Phi_{f}$ of ITO covered with a Cs compounds is decreased. This decrease is amplified by the annealing. It is shown that the thermal deposition under vacuum of the CBL induces a partial decomposition of the caesium compounds. In parallel, the formation of a compound with the In of ITO is put in evidence. This reaction is amplified by annealing, which allows obtaining IOPVCs with improved efficiency. The optimum annealing conditions is $150{ }^{\circ} \mathrm{C}$ for $5 \mathrm{~min}$.
\end{abstract}

\section{Introduction}

Nowadays, organic photovoltaic cells (OPVCs) are devices the most studied in the field of the photovoltaic energy owing to their promising properties, lightness, flexibility, semi transparency. Until today they are still in need of power conversion efficiency and stability improvement. Conventional OPVCs consist of an organic active material, containing an electron donor (ED) and an electron acceptor (EA), sandwiched by a high workfunction, conductive and transparent electrode as the anode, such as indium tin oxide (ITO) and a low work function metal, such as Al, as the cathode. In this conventional architecture, ITO is the bottom electrode, deposited onto the substrate, while the cathode is the top electrode [1].

More recently, inverted OPVCs with modified ITO as the transparent cathode and a high work function metal as the anode were studied. In this architecture the anode is the top electrode. It allows the use of an air stable high

\footnotetext{
${ }^{a}$ e-mail: jean-christian.bernede@univ-nantes.fr
}

work function material as top electrode to improve the air stability of the cells [2-4].

Efficient charge collections are usually achieved through electrode buffer layers. As a matter of fact, for efficient charge collection, work functions of cathode and anode must be matched to the lowest unoccupied molecular orbital (LUMO) of acceptor and the highest occupied molecular orbital (HOMO) of donor, respectively. Buffer layers (BF) are necessary in view of the difficulties in organic optoelectronic devices of the charge carrier transport between the organic materials and the electrodes. In the case of the anode/electron donor contact, a common solution is to introduce a thin anode buffer layer (ABL), which adjusts the electronic behaviour of the adjacent materials. We have shown that an ultra-thin $(0.5 \mathrm{~nm}) \mathrm{Au}$ film and or a thin $(4 \mathrm{~nm}) \mathrm{MoO}_{3}$ film introduced between the anode and the organic material can be used to improve the devices performances [5-7] and we have used $\mathrm{MoO}_{3}$ as ABL in the OPV studied here.

In the case of inverted OPVCs (IOPVCs) it was shown that the use of a $\mathrm{MoO}_{3}$ layer thick of $6 \mathrm{~nm}$ allows obtaining 
efficient hole collection whatever is the metal of the anode $[8,9]$. The main aim of the present work being the study of the interface cathode/EA, we have used this classical $\mathrm{MoO}_{3}$ /anode hole collecting structure, with $\mathrm{Al}$ metal electrode. We have focused our interest on the effect of cathode buffer layer (CBL) based on caesium compounds, $\mathrm{CsI}$ and $\mathrm{Cs}_{2} \mathrm{CO}_{3}$. More precisely we have studied the effect of the annealing temperature of the ITO/caesium compound structure on the electron collection efficiency. We show that the improvement of the efficiency of the caesium compound as CBL is related to CBL/ITO chemical reaction during the annealing process.

\section{Experimental details}

The cells were fabricated onto ITO coated glass substrates with a sheet resistance of about $25 \Omega$ /square. Here the ITO was used as cathode. The standard substrate dimensions were $25 \mathrm{~mm}$ by $25 \mathrm{~mm}$. Since ITO covered the whole glass substrates, some ITO must be removed to obtain the under electrode. After masking a broad band of $25 \mathrm{~mm}$ by $20 \mathrm{~mm}$, the ITO was etched by using $\mathrm{Zn}$ powder $+\mathrm{HCl}$ as etchant $[8,9]$. After scrubbing with soap, the ITO coated substrates were rinsed in running deionised water. Then the substrates were dried with an air flow and then loaded into a vacuum chamber $\left(10^{-4} \mathrm{~Pa}\right)$. Deposition rate and film thickness were measured in situ by quartz monitor, after calibration for each material used. The organic donor/acceptor couple used is copper phthalocyanine $(\mathrm{CuPc}) /$ fullerene $\left(\mathrm{C}_{60}\right)$, the $\mathrm{ABL}$ is, as said above, $\mathrm{MoO}_{3}$, while the $\mathrm{CBL}$ is either $\mathrm{CsI}$ or $\mathrm{Cs}_{2} \mathrm{CO}_{3}$. The Cs compound, $\mathrm{C}_{60}, \mathrm{CuPc}, \mathrm{MoO}_{3}$ films were successively sublimated under vacuum and finally the metal anode was evaporated on the top of the device giving the following inverted OPVC:ITO/CBL/C 60 (40 nm)/CuPc $(35 \mathrm{~nm}) / \mathrm{MoO}_{3}(6 \mathrm{~nm}) / \mathrm{Al}(120 \mathrm{~nm})$. The top electrode was deposited through a mask with $2 \times 10 \mathrm{~mm}^{2}$ active area.

Before deposition of the organic layers the ITO/Cs compound structures were annealed for $5 \mathrm{~min}$ at temperature between room temperature and $200{ }^{\circ} \mathrm{C}$ under argon flux. The effect of annealing temperature on the OPVCs performances, and on the properties of the bilayer ITO/Cs compound were studied.

The morphology of the different structures used as cathode was observed through scanning electron microscopy (SEM) with a JEOL 7600F. AFM images on different sites of the films were taken ex-situ at atmospheric pressure and room temperature. All measurements have been performed in tapping mode (Nanoscope IIIa, Veeco, Inc.). Classical silicon cantilevers were used (NCH, nanosensors). The average force constant and resonance were approximately $40 \mathrm{~N} / \mathrm{m}$ and $300 \mathrm{kHz}$, respectively. The cantilever was excited at its resonance frequency. These structural characterizations were performed at the "Centre de micro-caractérisation de l'Université de Nantes".

XPS measurements were carried out at room temperature. An Axis Nova instrument from Kratos Analytical spectrometer with $\mathrm{Al} \mathrm{K} \alpha$ line $(1486.6 \mathrm{eV})$ as excitation source has been used. The core level spectra were acquired with an energy step of $0.1 \mathrm{eV}$ and using a constant pass energy mode of $20 \mathrm{eV}$, to obtain data in a reasonable experimental time (energy resolution of $0.48 \mathrm{eV}$ ). Concerning the calibration, binding energy for the $\mathrm{C} 1 \mathrm{~s}$ hydrocarbon peak was set at $284.6 \mathrm{eV}$. The pressure in the analysis chamber was maintained lower than $10^{-7} \mathrm{~Pa}$. The background spectra are considered as Shirley type.

For comparison, OPVCs with CsI, $\mathrm{Cs}_{2} \mathrm{CO}_{3}$ and without CBL were realized during the same deposition process. Successive (3-4) depositions were done for each configuration, which corresponds to 9 to 12 OPVCs, in order to check the reproducibility of the results.

The work function $\left(\Phi_{f}\right)$ of the ITO electrode and CBL are evaluated using cyclic voltammetry. Cyclic Voltammetry is an electrochemical method for determination of oxidation and reduction states. The working electrode (here ITO sample), dipped in an electrolyte solution (Acetonitrile containing $0.1 \mathrm{M}$ tetrabutylammonium tetrafluoroborate), is biased with respect to the reference electrode $(\mathrm{Ag} / \mathrm{AgCl}(3 \mathrm{M} \mathrm{NaCl}))$, which has a known potential. When the bias reaches the difference between the reference electrode and oxidation potential of the sample, the electrode is oxidized and the current is recorded at the counter electrode. Similarly, when the bias overcomes the reduction potential, relative to the reference, the electrode is reduced. A linear voltage ramp is used in the sweep. Linear ramping potential starting from $0 \mathrm{~V}$ up to a pre-defined limiting value with a scan rate of $50 \mathrm{mV} / \mathrm{s}$ and recorded the current. The optimised switching potential is $2 \mathrm{~V}$ for this experiment. At this potential, the direction of the potential scan is reversed and the current is again recorded. The sweep is repeated several times between the two limiting potentials. A three electrodes cell configuration with $\mathrm{Pt}$ as the counter electrode is used for this work. Threeelectrodes configuration allows one electrode to be studied in isolation, without complications from the electrochemistry of the other electrodes. The instrument used is Zhaner make Electrochemical workstation (IM6ex).

The Ionization potential is calculated from the onset Oxidation potential using the equation

$$
I P=E o x^{\text {onset }}+4.4 \mathrm{eV} .
$$

The onset potentials are determined from the intersection of the two tangents drawn at the rising current and baseline charging current of the $\mathrm{CV}$ traces. The work function of ITO is taken as equal to ionization potential (IP), as it is assumed that there is no band bending at ITO interface and the injection barrier, $\Delta E_{h} \sim 0$.

\section{Results and discussion}

Figure 1 shows the photovoltaic response of typical IOPVCs using different cathode configurations. Table 1 shows that the post-deposition annealing temperature of the cathode buffer layer plays a major role in the device performances. 
Z. El Jouad: Improved electron collection in fullerene via caesium iodide or carbonate

Table 1. Performances of the OPVCs with different cathode buffer layers and after different annealing.

\begin{tabular}{cccccc}
\hline Buffer layer & Annealing temperature $\left({ }^{\circ} \mathrm{C}\right)$ & $J_{s c}\left(\mathrm{~mA} / \mathrm{cm}^{2}\right)$ & $V_{o c}(\mathrm{~V})$ & $F F(\%)$ & $\eta(\%)$ \\
\hline $\mathrm{CuI}^{*}$ & - & 6.09 & 0.43 & 51 & 1.35 \\
\hline- & - & 2.99 & 0.42 & 50 & 0.63 \\
\hline $\mathrm{CsI}$ & - & 1.52 & 0.32 & 35 & 0.17 \\
$\mathrm{CsI}$ & 100 & 2.49 & 0.37 & 41 & 0.38 \\
$\mathrm{CsI}$ & 150 & 3.53 & 0.43 & 55 & 0.84 \\
$\mathrm{CsI}$ & 200 & 4.05 & 0.40 & 45 & 0.81 \\
\hline $\mathrm{CsCO}_{3}$ & - & 1.63 & 0.28 & 35 & 0.16 \\
$\mathrm{CsCO}_{3}$ & 100 & 2.08 & 0.30 & 40 & 0.25 \\
$\mathrm{CsCO}_{3}$ & 150 & 3.12 & 0.40 & 51 & 0.63 \\
$\mathrm{CsCO}_{3}$ & 200 & 3.80 & 0.38 & 45 & 0.65 \\
\hline
\end{tabular}

*Classical cell configuration: ITO/CuI/CuPc/C60/Alq $/ \mathrm{Al}$.

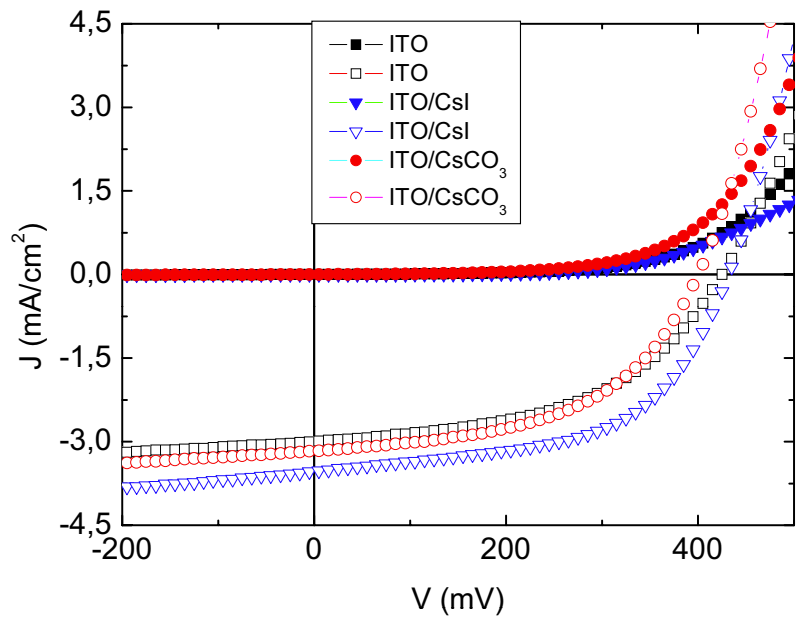

Fig. 1. $J-V$ characteristics of OPVCs with different cathode buffer layers: ITO $(\boldsymbol{\square})$, ITO/CsI $(\mathbf{\nabla})$ and ITO $/ \mathrm{Cs}_{2} \mathrm{O}_{3}(\bullet)$ after annealing at $150{ }^{\circ} \mathrm{C}$ of the structure ITO/Cs compound.

Firstly, we can see that a minimum annealing temperature is necessary for the buffer layer is effective. Below this temperature the power conversion efficiency $(\eta)$ of the IOPVCs is smaller than that obtained without CBL. Similar results were already achieved, for instance in the case of $\mathrm{Cs}_{2} \mathrm{CO}_{3}$, it was attributed to its low conductivity [10]. Actually, when the annealing temperature is insufficient, the IOPVCs show poor short circuit current density, $J_{s c}$, open circuit voltage, $V_{o c}$, and fill factor, $F F$, implying that the Cs compound CBL provide poor function in terms of electron extraction and transport to the cathode [11]. Secondly, we can also note that the minimum annealing temperature required is $150{ }^{\circ} \mathrm{C}$ for $5 \mathrm{~min}$. For higher annealing temperatures we note a tendency of stabilization of the IOPVCs performances. The variation in devices performances in not large in terms of $V_{o c}$ and $F F$. However the variation in $J_{s c}$ is obvious, due to the presence or not of a CBL and of its annealing temperature. Maximum $J_{s c}$ of $3.53 \mathrm{~mA} / \mathrm{cm}^{2}$ and $3.80 \mathrm{~mA} / \mathrm{cm}^{2}$ are obtained after annealing $5 \mathrm{~min}$ at $150{ }^{\circ} \mathrm{C}$ for $\mathrm{CsI}$ and $200{ }^{\circ} \mathrm{C}$ for $\mathrm{Cs}_{2} \mathrm{CO}_{3}$, respectively.

It is known that the photocurrent of the IOPVCs depends on the light absorption, exciton dissociation, carrier
Table 2. Performances of the OPVCs with different CsI thickness after an annealing of $5 \mathrm{~min}$ at $150{ }^{\circ} \mathrm{C}$.

\begin{tabular}{ccccc}
\hline $\begin{array}{c}\text { CsI thickness } \\
(\mathrm{nm})\end{array}$ & $\begin{array}{c}J_{s c} \\
\left(\mathrm{~mA} / \mathrm{cm}^{2}\right)\end{array}$ & $\begin{array}{c}V_{o c} \\
(\mathrm{~V})\end{array}$ & $\begin{array}{c}F F \\
(\%)\end{array}$ & $\begin{array}{c}\eta \\
(\%)\end{array}$ \\
\hline 1 & 3.01 & 0.42 & 53 & 0.67 \\
1.5 & 3.53 & 0.43 & 55 & 0.84 \\
3 & 2.40 & 0.41 & 32 & 0.32 \\
\hline
\end{tabular}

transport and collection at electrodes. Here, due to the same ED/EA couple in each device, it can be supposed that exciton diffusion, dissociation and carrier transport are the same for all IOPVCs. Moreover the same anode configuration being used for all devices, the differences in the $J_{s c}$ values should mainly due to cathode electron collection efficiency. So, in order to understand the origin of the IOPVCs improvement, the different CBL/ITO structures were investigated.

As the light is incident from the ITO electrode, a possible source of $J_{s c}$ modification is the optical transmittance of the cathode. All samples, with or without CBL, show high transparency with transmittance above $90 \%$ in the visible range (not shown here). It shows that there is no contribution of the optical properties of the cathode to the variation of the $J_{s c}$ value.

The electronic collection is also related to the passage of free electrons through the EA/CBL/ITO interface, before they are collected by the cathode. Therefore the conductivity of the CBL is significant for charge collection efficiency. The conductivity of the CBL used being very small, the electrons can cross this layer by tunnel effect. It is known that for thickness higher than $2 \mathrm{~nm}$ a fast decrease of the tunnelling current is observed, which justifies that the highest efficiency is obtained with CBL thickness of $1.5 \mathrm{~nm}$. For thicker films, $J_{s c}$ decreases due to limited tunnel effect. For thinner films, the CBL is strongly discontinuous which justifies its limited effect (Tab. 2).

Lastly, the energy alignment at the EA/cathode interface is decisive to the electron collection. In the case of poor band matching, the series resistance increases and $V_{o c}$ is limited.

The series resistance of the different IOPVCs varies with the cathode structure. As expected, it decreases when $J_{s c}$ increases. For instance it decreases from $R s=18 \Omega$ 

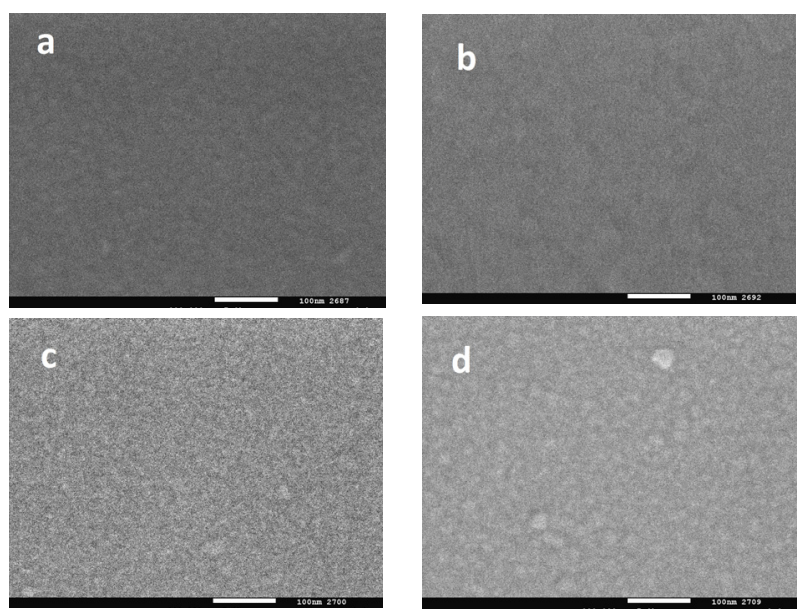

Fig. 2. Surface visualisation of ITO/CsI cathode not annealed (a) and annealed at $100{ }^{\circ} \mathrm{C}(\mathrm{b}), 150{ }^{\circ} \mathrm{C}$ (c) and $200{ }^{\circ} \mathrm{C}(\mathrm{d})$.
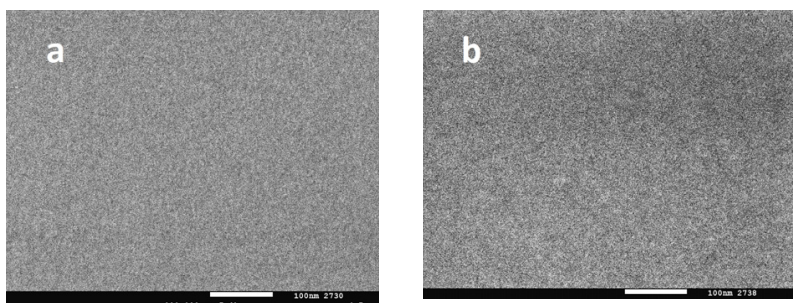

Fig. 3. Surface visualisation of ITO/ $\mathrm{Cs}_{2} \mathrm{CO}_{3}$ cathode not annealed (a) and annealed at $150{ }^{\circ} \mathrm{C}(\mathrm{b})$.

without $\mathrm{CBL}$ to $8 \Omega$ when the $\mathrm{CsI} \mathrm{CBL}(1.5 \mathrm{~nm})$ is annealed at $150{ }^{\circ} \mathrm{C}$, indicating that the annealed structures are more favourable to electron collection. Also $V_{o c}$ increases with the annealing temperature, at least up to the optimum temperature, which testifies of an improvement of the band matching.

In order to investigate more precisely the effect of the nature of the CBL and of the annealing treatment, on the ITO/CBL structure properties we proceed to some specific characterizations, SEM, AFM, XPS studies and $\Phi_{M}$ measurements.

We first consider the SEM images obtained for the surfaces of the ITO/CBL structures (Figs. 2 and 3) and the AFM topographic images obtained for the surfaces of these structures (Figs. 4 and 5).

Figures 2 and 3 show the SEM images of the CsI and the $\mathrm{Cs}_{2} \mathrm{CO}_{3} \mathrm{CBL}$ onto the ITO electrode after annealing treatment or not. Without or with annealing the surfaces of the structures are fairly smooth and homogeneous even if some faint features seem appear when the annealing temperature increases.

The AFM topographic images of the ITO/CBL structures are shown in Figures 4 and 5. Before annealing the root mean square (rms) roughness is of $2.8 \pm 0.2 \mathrm{~nm}$ in the case of CsI and $3.5 \pm 0.2 \mathrm{~nm}$ in the case of $\mathrm{Cs}_{2} \mathrm{CO}_{3}$. After annealing, whatever the annealing temperature, the surface is smoothed. The rms value is $1.9 \pm 0.2 \mathrm{~nm}$ in the case of $\mathrm{CsI}$ and $1.7 \pm 0.2 \mathrm{~nm}$ for $\mathrm{Cs}_{2} \mathrm{CO}_{3}$. These results do not confirm the visual impression given by the SEM study.
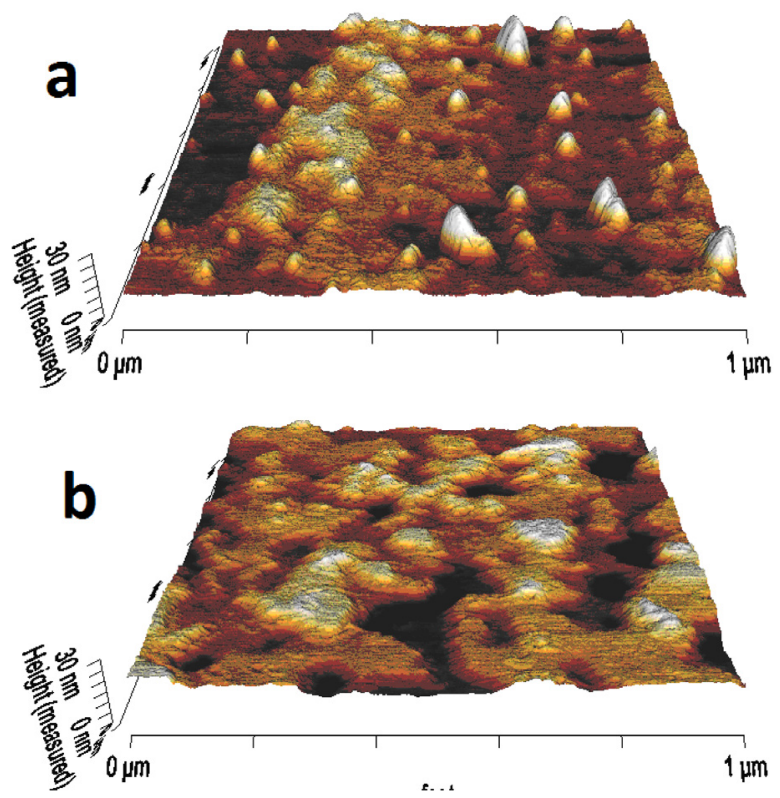

Fig. 4. AFM images of ITO/CsI cathode before (a) and after (b) annealing at $100{ }^{\circ} \mathrm{C}$.
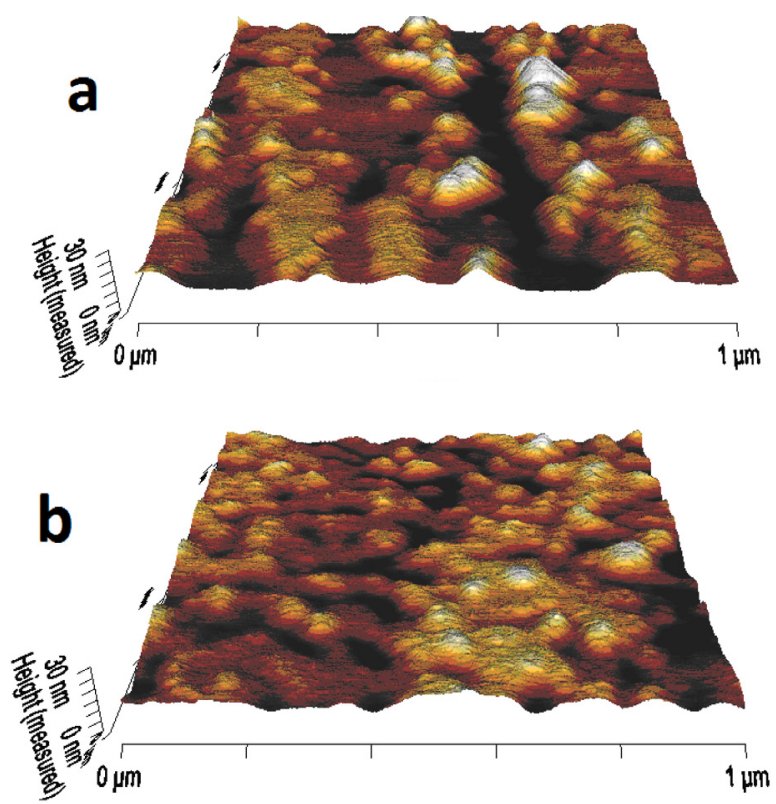

Fig. 5. AFM images of ITO/ $\mathrm{Cs}_{2} \mathrm{CO}_{3}$ cathode before (a) and after (b) annealing at $100{ }^{\circ} \mathrm{C}$.

Therefore the surface morphology studies of the ITO/CBL indicate that the nature of the $\mathrm{CBL}, \mathrm{CsI}$ or $\mathrm{Cs}_{2} \mathrm{CO}_{3}$, and its annealing temperature have only a small effect on the surface morphology of the ITO/CBL structures. This suggests that, the surface morphology of the structures can hardly explain the different behaviours, so we preceded in XPS measurements.

About quantitative analysis, there is some uncertainty on the measures for the $\mathrm{Cs}_{2} \mathrm{CO}_{3}$ due to the transfer in room air from gloves box, where we proceed to the annealing, to the XPS apparatus, which induces some oxygen 


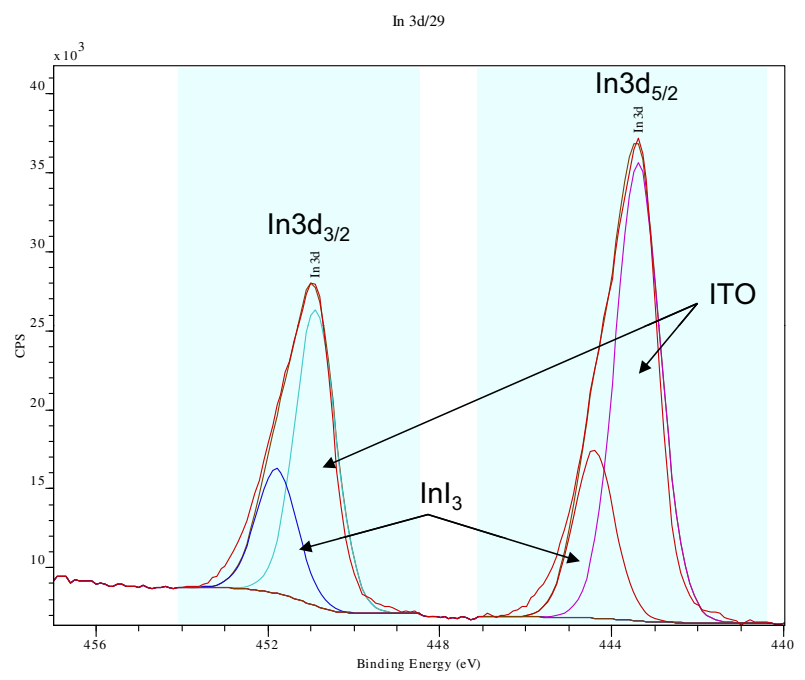

Fig. 6. Decomposition of the In $3 d$ XPS spectra of CsI/ITO structure annealed at $100{ }^{\circ} \mathrm{C}$.

and carbon contamination. Moreover, the $\mathrm{Cs}_{2} \mathrm{CO}_{3}$ being very thin, the oxygen of ITO, the bottom layer, is also detected. This kind of problem does not exist in the case of the quantitative analysis of CsI and we found that the deposited films are systematically iodine deficient. Without annealing the relative atomic iodine concentration is only $15 \%$ and therefore that of Cs is 85 at.\%. After annealing the iodine atomic concentration decreases progressively when the annealing temperature increases: 11 at.\% after 5 min at $100{ }^{\circ} \mathrm{C}, 9$ at. $\%$ at $150{ }^{\circ} \mathrm{C}$ and 7 at. $\%$ at $200{ }^{\circ} \mathrm{C}$. It means that the vacuum deposition, and the annealing, of CsI induces, at least partly, its decomposition. This fact is in good agreement with earlier studies that show the tendency of Cs compounds to decompose during vacuum deposition for $\mathrm{Cs}_{2} \mathrm{CO}_{3}[12,13]$ and $\mathrm{CsI}[14]$. Moreover, it should be noted that, the CBL layer being thin $(1.5 \mathrm{~nm})$, the elements of the bottom layer are systematically detected. For instance the doublet In $3 d$ of the indium of ITO is clearly visible. It can be seen in Figure 6 that the doublet In $3 d$ corresponds to two doublets. The first one, with In $3 d 5 / 2=444.5 \pm 0.2 \mathrm{eV}$, corresponds to the indium bounded to oxygen in ITO, the second one, at $\operatorname{In} 3 d 5 / 2=445.5 \pm 0.2 \mathrm{eV}$, can be attributed to some indium bounded to iodine in the form $\mathrm{InI}_{3}$ [15]. Moreover the ratio $\mathrm{In}_{\mathrm{ITO}} / \mathrm{In}_{\mathrm{InI}_{3}}$ decreases significantly when the annealing temperature increases from 4 before annealing to 2 after annealing at $200{ }^{\circ} \mathrm{C}$ (Tab. 3). The binding energy of the iodine doublet is In $3 d 5 / 2=618.2 \mathrm{eV}$ and 619.1 when it is bounded as CsI [16] and $\mathrm{InI}_{3}$ [15], respectively. As a matter of fact the iodine signal corresponds to two doublets the main one, situated at $618.8 \mathrm{eV}$, can be attributed to the indium compound. The second one situated at around 618.3 , can be attributed to CsI (Fig. 7). All this means that during the annealing there is $\mathrm{InI}_{3}$ formation. In the case of $\mathrm{Cs}_{2} \mathrm{CO}_{3}$, the reaction is not so easy to put in evidence. However, here also, the $\operatorname{In} 3 d$ doublet can be decomposed into two doublets, the one situated at $444.3 \mathrm{eV}$ corresponds at ITO and the second one,
Table 3. Variation of the ratio $\mathrm{In}_{\mathrm{ITO}} / \mathrm{In}_{x}$ with the annealing temperature.

\begin{tabular}{lcccc}
\hline Annealing temperature $\left({ }^{\circ} \mathrm{C}\right)$ & 25 & 100 & 150 & 200 \\
\hline $\mathrm{In}_{\text {ITO }} / \operatorname{In}_{\text {InI }_{3}}$ & 4.0 & 3.0 & 2.15 & 2.0 \\
$\mathrm{In}_{\text {ITO }} / \operatorname{In}_{\mathrm{In}(\mathrm{OH}) n}$ & 4.4 & 3.6 & 2.8 & 2.4 \\
\hline
\end{tabular}

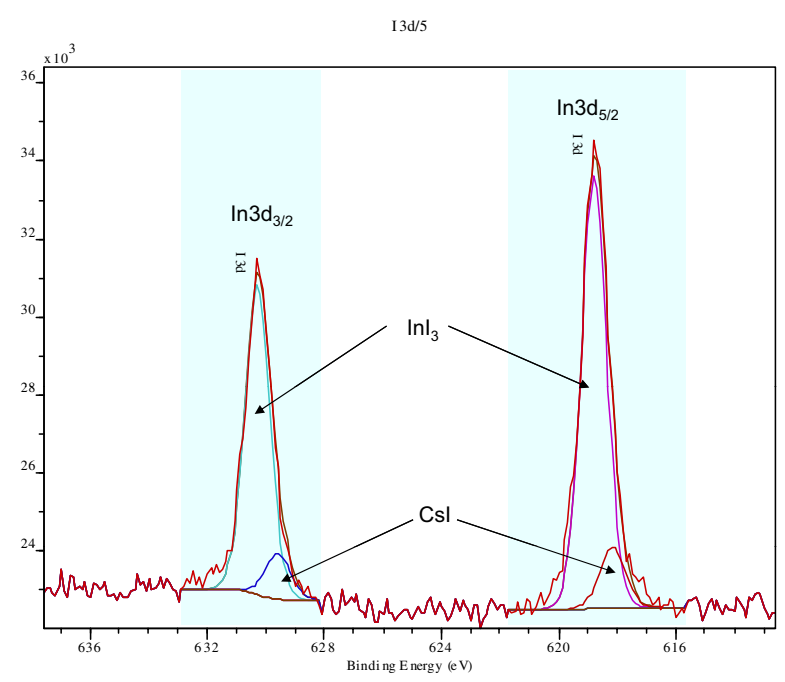

Fig. 7. Decomposition of the I3d XPS spectra of CsI/ITO structure annealed at $100{ }^{\circ} \mathrm{C}$.

which is smaller (Tab. 3) situated at 445 corresponds to some hydroxide compound such as $\operatorname{In}(\mathrm{OH})_{3}$ [17]. During the annealing, as shown in Table 3 , the contribution of the doublet corresponding to the ITO decreases for the benefit of the doublet corresponding to the hydroxide. This is confirmed by the evolution of the peak $\mathrm{O} 1 s$ of the oxygen. As it can be seen in Figure 8, before annealing and after annealing at $100{ }^{\circ} \mathrm{C}$ the $\mathrm{O} 1 s$ peak can be decomposed in three components, however their relative intensities are modified by the annealing. The peak situated at $531.6 \mathrm{eV}$ corresponds to $\mathrm{Cs}_{2} \mathrm{CO}_{3}$ [18], that at $529.5 \mathrm{eV}$ corresponds to ITO and that at $530.6 \mathrm{eV}$ can be attributed to $\mathrm{In}(\mathrm{OH})_{3}$. The relative intensity of this last contribution increases from 14 at.\% before annealing to 27 at.\% after annealing at $100{ }^{\circ} \mathrm{C}$ which corroborates the fact that the chemical interaction between the caesium compounds CBL with ITO is increased by the annealing process. This discussion is consolidated by the evolution of the binding energy Cs. Actually, the Cs3d doublets shift slightly toward higher binding energy upon annealing, which suggests that decomposition of Cs compounds occurs [18].

The cyclic voltammograms of ITO and all other samples with CBL layers are shown in Figures 9a-9g. The complete CV cycle is necessary to confirm the correctness of the experimental data and we got excellent CV traces for these samples as seen from Figure 9. To calculate the work function from the CV the onset oxidation potential is evaluated from the CV graph. This is usually done by noting the potential corresponding to the intersection of the two tangents drawn at the rising current and baseline charging current of the $\mathrm{CV}$ traces. But in this case, 
EPJ Photovoltaics

Table 4. Variation of $\Phi_{f}$ with the nature of anode and annealing temperature.

\begin{tabular}{ccccc}
\hline $\begin{array}{c}\text { No. in } \\
\text { Figure } 9\end{array}$ & Sample & $\begin{array}{c}\text { Annealing } \\
\text { temperature }\left({ }^{\circ} \mathrm{C}\right)\end{array}$ & $\begin{array}{c}\text { Work } \\
\text { function }(\mathrm{eV})\end{array}$ & $\begin{array}{c}\text { Tolerance } \\
(\mathrm{eV})\end{array}$ \\
\hline 1 & ITO & - & 4.51 & \pm 0.01 \\
2 & ITO-CsCO $_{3}$ & - & 4.49 & \pm 0.01 \\
3 & ITO-CsCO $_{3}$ & 100 & 4.42 & \pm 0.02 \\
4 & ITO-CsCO & 150 & 4.31 & \pm 0.01 \\
5 & ITO-CsI & - & 4.41 & \pm 0.02 \\
6 & ITO-CsI & 100 & 4.40 & \pm 0.01 \\
7 & ITO-CsI & 150 & 4.38 & \pm 0.01 \\
\hline
\end{tabular}
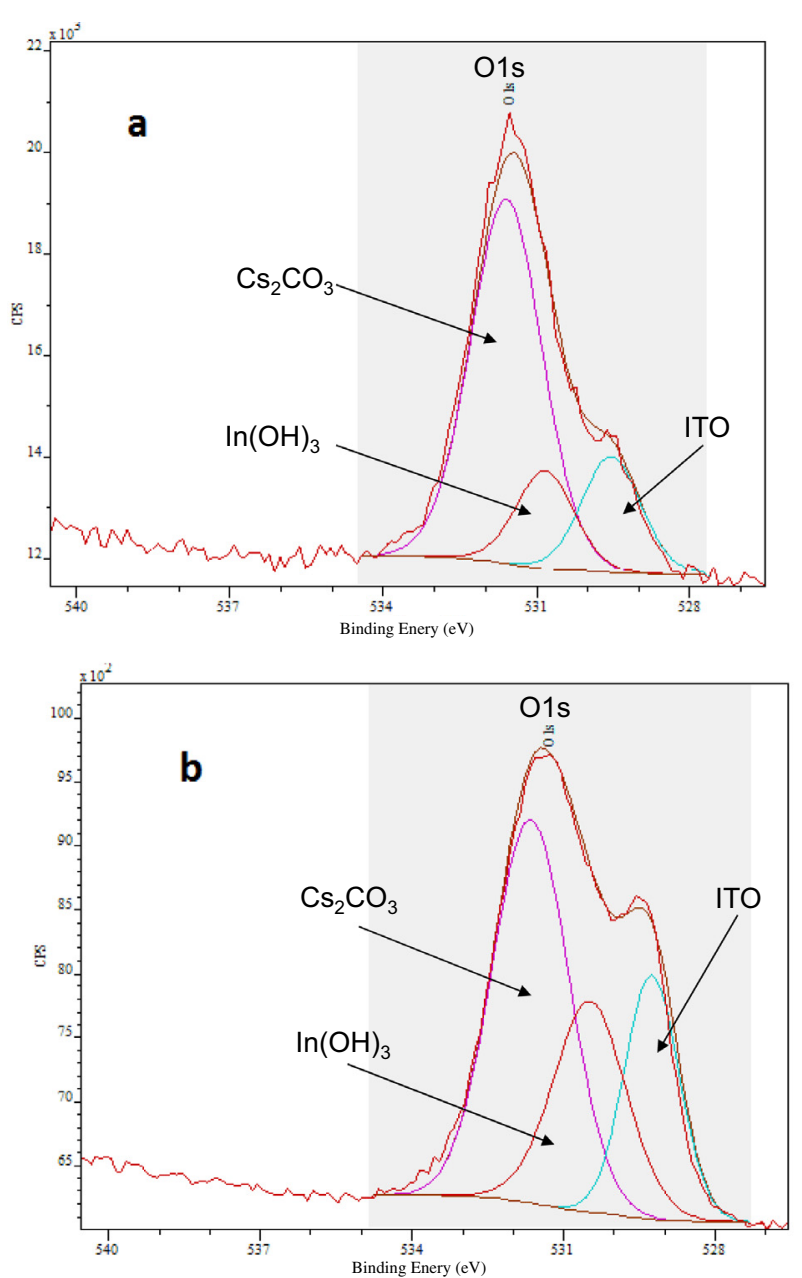

Fig. 8. Decomposition of the O1s XPS spectra of $\mathrm{Cs}_{2} \mathrm{CO}_{3} / \mathrm{ITO}$ structure before (a) and after (b) annealing at $100{ }^{\circ} \mathrm{C}$.

the required rising current peak is too small and thus CV graph is be magnified to see the correct appearance of the peak. Thus here the onset peak is found to be occurring between $-0.5 \mathrm{~V}$ to $+0.5 \mathrm{~V}$. Here baseline is considered as the $x$-axis because the charging is started from $0 \mathrm{~V}$.

Table 4 gives the deduced values of the work function. The measured values of the work function $\Phi_{f}$ of the different cathodes show that whatever the CBL used, it induces systematically a decrease of the value of $\Phi_{f}$ and that the more the temperature is raised, the higher is the reduction in work function (Tab. 4). Of course, the technique used to measure $\Phi_{f}$ may not be one with extreme precision. However, it gives a relative variation of $\Phi_{f}$. Band alignment and work functions in organic electronic materials are generally evaluated by three methods: cyclic voltammetry (CV), ultraviolet photoelectron spectroscopy (UPS) or Kelvin Probe techniques (KP). CV analysis employs the method of measurement of the reduction and oxidation potentials either for isolated molecules in solution or for thin films submerged in solvent, and gives the value of ionization potential. The working range of these measurements is limited [19] by the electrochemical stability of the solvent and values may not always correlate well with values observed at the solid state interfaces in actual devices. UPS analysis can provide both the ionization potential (IP), as well as its work function in ultrahigh vacuum (UHV). However, this method also has limitations [20-22] as the measurements made by UPS are extremely sensitive to surface conditions leading to a range of values reported for common materials due to variations in fabrication and handling history. Also it has been pointed out [19] that exposure of films to UHV conditions can also alter [23] the surface composition, particularly for metal oxide surfaces used in hybrid photovoltaics devices fabricated in ambient lab conditions. Often it has been found that the UPS determined value is about $0.3 \mathrm{eV}$ lower than the $\mathrm{KP}$ value.

It has also been pointed out [19] that the discrepancy between KP and UPS values is well-documented [23-26]. Variation in the reference values will directly contribute to the differences observed by UPS and KP. Further fundamental differences exist [24] in the work function measuring principles of KP and UPS. UPS measures that of the lowest energy electrons that escape the film surface upon excitation with the UV source and invariably gives only lowest work function in the measured area. On the other hand KP measures [24] the average work function of the area just below the probe. This naturally ends up in higher work function values for KP than that of UPS as surfaces would not be uniform for all practical purposes. Another major problem with UPS is the degradation of the surface at UHV as it may reduce [19] the quantity of volatile surface adsorbates on the films, resulting in a work function difference. In the case of KP, it has been reported [24] discrepancies between KP values measured with three different instruments. A very important draw back of KP was reported [24] as though it is more sensitive than UPS it fails in detecting ITOs with different surface treatments. However, it has been shown [27] that 
Z. El Jouad: Improved electron collection in fullerene via caesium iodide or carbonate
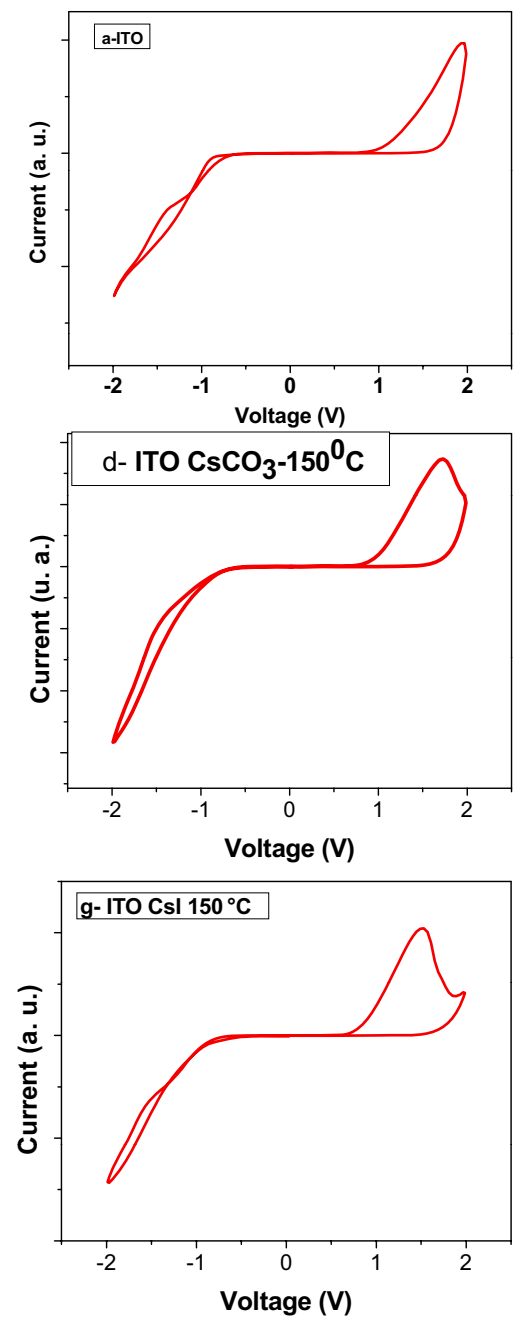
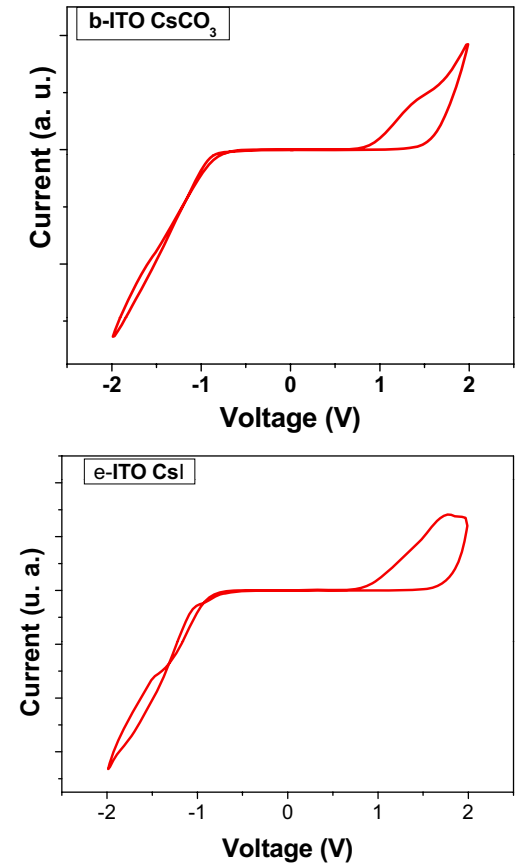
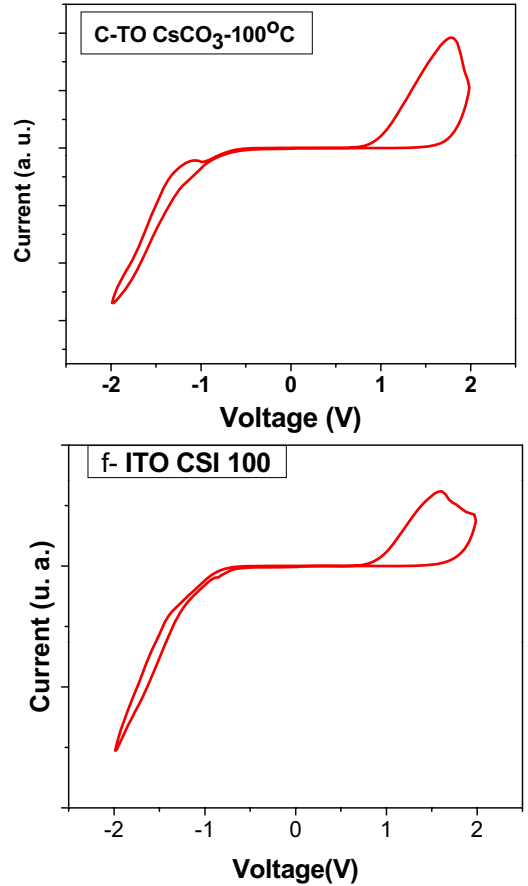

Fig. 9. Cyclic voltammograms of ITO and ITO coated with buffer layers.

$\mathrm{CV}$ does this nicely and convincingly. From the above discussion it is clear that none of these methods can be considered as absolute and all have distinct advantages and drawbacks. However the important thing is that the value of work function measured by all these three techniques differ only slightly in the range of 0.1 to $0.3 \mathrm{eV}$ only and while studying the variation of work function with respect to a parameter all are capable of similar trends. Thus, the $\mathrm{CV}$ measurement of work function presented here gives a more or less accurate estimation of the degree of variation of work function on modifying the ITO electrodes with buffer layers.

As a matter of fact, it was already shown that the use of a caesium compound as CBL induces a decrease of the work function, $\Phi_{f}$, of the cathode, which allows improving the band matching at the interface cathode electron acceptor [28, 29]. Xiao et al. [14] attribute this decrease of $\Phi_{f}$ to Cs-O bonds formation at the ITO surface. In the present work, we show that the indium of ITO reacts chemically with the caesium compound, which justifies this work function variation. The efficiency of the chemical reaction increases with the annealing temperature, which improve the decrease in $\Phi_{f}$ of the cathode.

\section{Conclusion}

We show that CsI is an efficient CBL between the ITO cathode and fullerene in inverted planar solar cells. It is as well, and even more, effective as $\mathrm{Cs}_{2} \mathrm{CO}_{3}$. When deposited under vacuum by thermal heating, the CsI is iodine deficient. This deficiency is amplified by the annealing to which it is necessary to submit the modified cathode to achieve efficient electron collection. Actually, we show by XPS analysis the presence of a chemical reaction between the indium of ITO and the anion of the caesium compound. This chemical reaction allows the decrease of the work function of the cathode. This decrease was checked through work function measurements using the cyclic voltammetry method. The efficiency of the IOPVCs was optimized by varying the annealing temperature and the CsI layer thickness. Obviously, the short circuit current $J_{s c}$ is the more sensible parameter. The best IOPVCs were obtained after an annealing of 5 min at $150{ }^{\circ} \mathrm{C}$, with a CsI thickness of $1.5 \mathrm{~nm}$. IOPVCs with $\mathrm{Cs}_{2} \mathrm{CO}_{3}$ were studied for comparison with CsI. The results suggest that $\mathrm{CsI}$ is, at least, as efficient as $\mathrm{Cs}_{2} \mathrm{CO}_{3}$ as $\mathrm{CBL}$ in planar organic photovoltaic cells. 
This work was supported by the France-Maroc contract: PHC Toubkal and the Hassan II Academy of Science and Technology (Morocco).

\section{References}

1. J.C. Bernède, J. Chil. Chem. Soc. 53, 1549 (2008)

2. C. Tao, S.P. Ruan, X.D. Zhang, G.H. Xie, L. Shen, X.Z. Kong, W. Dong, C.X. Liu, W.Y. Chen, Appl. Phys. Lett. 93, 193307 (2008)

3. C.Y. Jiang, X.W. Sun, D.W. Zhao, A.K.K. Kyaw, Y.N. Li, Sol. Energy Mater. Sol. Cells 94, 1618 (2010)

4. M. Hösel, R.R. Sondergaard, M. Jorgensen, F.C. Krebs, Energy Technol. 1, 102 (2013)

5. J.C. Bernède, L. Cattin, M. Morsli, Y. Berredjem, Sol. Energy Mater. Sol. Cells 92, 1508 (2008)

6. L. Cattin, S. Tougaard, N. Stephant, S. Morsli, J.C. Bernède, Gold Bull. 44, 199 (2011)

7. L. Cattin, F. Dahou, Y. Lare, M. Morsli, R. Tricot, K Jondo, A. Khelil, K. Napo, J.C. Bernède, J. Appl. Phys. 105, 034507 (2009)

8. F.-Z. Sun, A.-L. Shi, Z.-Q. Xu, H.-X. Wei, Y.-Q. Li, S.-T. Lee, J.-X. Tang, Appl. Phys. Lett. 102, 133303 (2013)

9. A.S. Yapi, L. Toumi, Y. Lare, G.M. Soto, L. Cattin, K. Toubal, A. Djafri, M. Morsli, A. Khelil, M.A. Del Valle, J.-C. Bernède, Eur. Phys. J. Appl. Phys. 50, 30403 (2010)

10. D.-W. Chou, K.-L. Chen, C.-J. Huang, Y.-J. Tsao, W.-R. Chen, T.-H. Meen, Thin Solid Films 536, 235 (2013)

11. Z.-Q. Xu, J.-P. Yang, F.-Z. Sun, S.-T. Lee, Y.-Q. Li, Organic Electronics 13, 697 (2012)

12. Y. Li, D.-Q. Zhang, L. Duan, R. Zhang, L.-D. Wang, Y. Qiu, Appl. Phys. Lett. 90, 012119 (2007)

13. K. Morii, T. Kawase, S. Inoue, Appl. Phys. Lett. 92, $213304(2008)$

14. T. Xiao, W. Cui, M. Cai, W. Leung, J.W. Anderegg, J. Shinar, R. Shinar, Org. Electron. 14, 267 (2013)
15. B.H. Freeland, J.J. Habeed, D.G. Tuck, Can. J. Chem. 55, 1528 (1977)

16. W.E. Morgan, J.R. Van Wazer, W.J. Stec, J. Am. Chem. Soc. 95, 751 (1997)

17. M. Faur, M. Faur, D.T. Jayne, M. Goradia, C. Goradia, Surf. Interface Anal. 15, 641 (1990)

18. H.-H. Liao, L.-M. Chen, Z. Xu, G. Li, Y. Yang, Appl. Phys. Lett. 92, 173303 (2008)

19. R.J. Davis, M.T. Lloyd, S.R. Ferreira, M.J. Bruzek, S.E. Watkins, L. Lindell, P. Sehati, M. Fahlman, J.E. Anthony, J.W.P. Hsu, J. Mater. Chem. 21, 1721 (2011)

20. Y. Park, V. Choong, Y. Gao, B.R. Hsieh, C.W. Tang, Appl. Phys. Lett. 68, 2699 (1996)

21. C.C. Wu, C.I. Wu, J.C. Strum, A. Kahn, Appl. Phys. Lett. 70, 1348 (1997)

22. K. Sugiyama, H. Ishii, Y. Ouchi, K. Seki, J. Appl. Phys. 87, 295 (2000)

23. M. Lira-Cantu, F.C. Kreb, Sol. Energy Mater. Sol. Cells 90, 2076 (2006)

24. J.S. Kim, B. Lagel, E. Moons, N. Johansson, I.D. Baikie, W.R. Salaneck, R.H. Friend, F. Cacialli, Synth. Met. 111112, 311 (2000)

25. W. Osikowicz, M.P. de Jong, S. Braun, C. Tengstedt, M. Fahlman, W.R. Salaneck, Appl. Phys. Lett. 88, 193504 (2006)

26. E. Ito, H. Oji, N. Hayashi, H. Ishii, Y. Ouchi, K. Seki, Appl. Surf. Sci. 175-176, 407 (2001)

27. H.D. Kwak, D.S. Choi, Y.K. Kim, B.C. Sohn, Mol. Cryst. Liq. Cryst. 370, 47 (2001)

28. Y.-I. Lee, J.-H. Youn, M.-S. Ryu, J. Kim, H.-T. Moon, J. Jang, Sol. Energy Mater. Sol. Cells 99, 3276 (2011)

29. B. Park, J.C. Shin, C.Y. Cho, Sol. Energy Mater. Sol. Cells 108, 1 (2013)

30. M.M. Beerbom, B. Lagel, A.J. Cascio, B.V. Doran, R. Schlaf, J. Electron. Spectrosc. Relat. Phenom. 152, 12 (2006) 